\title{
Psychological distress and resilience: a study of prevalence and association among school-attending adolescents in Benin-City
}

\author{
OO Akanni, AN Otakpor
}

\section{Introduction}

Resilience is the process of negotiating, managing, and adapting to significant sources of stress or trauma (1). Resilience (or resiliency) has alternatively been investigated as an individual's character trait or as an epiphenomenon of adaptive temperament, as the use of emotional resources for adapting to adversity, or as a process that drives a person to grow through adversity and disruption (2). In recent times, researchers have argued that resilience can be assessed and studied at any time in a person's life, rather than only during periods of extreme stress, since resilience is not a state but an enduring personality trait throughout the individual's life span (3).

Adolescence corresponds to the period between the ages of 10 and 19 years, and is a critical phase of biological, social, and psychological transitions; it is a period of change and challenges, with susceptibility to development of psychological distress (4-5). Prevalence studies of psychological distress and it's impact among adolescents in Nigeria is limited, with varying rates of distress reported, ranging between $15 \%$ and $50 \%$ (6-8, Fatoye, 1998 and Ikegwuonu, 2009, unpublished report). Resilience to distress in adolescents has been conflictingly reported to be associated with high rates of depression and anxiety on one hand (9-10), and also with lower rates of anxiety, depressive symptoms, and suicidal ideas (11-13). Family factors, such as polygamy (Fatoye, 1998, unpublished report), lower socio-economic class, divorce and separation, have also been reported as risk factors for the development of psychological problems in adolescents (14-17).

The aims of this study were to describe the rates of psychological distress among school-going adolescents in Nigeria, and to explore associations (if any) between variables such as socio-demographic characteristics, family factors, psychological resilience on one hand, and the presence of psychological distress.

\section{Methods}

\section{Study participants}

Adolescent students aged 16-19 yrs in the final year of the Senior Secondary School in Oredo Local Government Area (LGA) were selected by a multi-stage random sampling. The first stage was the selection of Oredo LGA by simple random sampling (balloting) from the 3 LGAs spread across the city; then the selection of 18 mixedgender participating schools (since all the private schools in Oredo LGA are mixed-gender schools) from the LGA by stratifying the schools into public and private schools to ensure appropriate school representation; stage three used proportional representation method to calculate the number of students to be selected from each of the participating schools; finally, using the class register, simple random sampling technique was used to select the students from each arm of the final year classes. A detailed description of how participants were recruited has been reported previously (18).

The sample size was calculated to be 346 using the Fisher's formula (19), based on a prevalence rate of 34.2\% for adolescent psychological distress (Ikegwuonu, 2009, unpublished report), with a 5\% degree of accuracy. However, the final sample size was increased in order to improve the power of the study.

Students below 18 years who consented to participate, together with signed written consent from their parents/ guardians, and students aged 18yrs-19 yrs who gave written informed consent were recruited for the study. Students with a medical history of chronic physical illnesses such as epilepsy, sickle cell disease, and physical handicaps that are known to increase psychosocial morbidity, were excluded (20).

\section{Outcomes of interest and tools}

A specifically designed data collection sheet was used to obtain socio-demographics and family-related variables. The General Health Questionnaire (GHQ-28) developed by Goldberg (1972), was used to screen for mental health morbidity (21). The GHQ-28 is a self- rated, factor-derived 28-item screening instrument, where each question has four possible responses, of which the respondent is asked to choose the single best response that most closely fits how he/she has been feeling recently. The conventional Likert scoring was used in which the first two responses are scored zero while the last two are scored " 1 ”. A total score of 5 or more is indicative of 'GHQ-caseness' or probable psychological distress. It has been validated for use in Nigeria, among older adolescents (22-25). 
The Resilience Scale (RS-14) developed by Wagnild and Young (1993) was adapted and used to measure the degree of each participant's resilience (26). The RS-14 has been widely used across different age groups and settings $(1,30)$. The RS-14 was adapted for local use by administering it to 106 respondents, during a pilot study conducted 2 months prior to the main study. Analysis was conducted to determine the internal consistency of the RS-14; the Cronbach alpha was 0.55, which was considered low. Certain items on the scale were noted to have low item-total correlation, and therefore only. Eight items in the scale that had a correlation of below 0.30 were omitted (28), and the remaining 6 (items 8-10, 12-14) yielded an improved Cronbach alpha of 0.65 . Factor analysis using principal component analysis followed by Varimax rotation procedure was computed for the 6items, yielding 2 factors. The concurrent validity of the 6-item Resilience Scale (RS-Ad) was established by correlating scores of the RS-14 with the RS-Ad. The RS-Ad showed a significant correlation with the RS-14, with a modestly strong degree of association $(r=0.74$, $\mathrm{p}=0.00$ ), thus making it acceptable for the study. This version of the scale (RS-Ad) with 6-items was used for the main study. Responses were made on a 7-point scale, with higher scores indicating greater resilience.

\section{Procedure}

Ethical approved for the study was obtained from the University of Benin Teaching Hospital's ethics committee, and necessary permission to conduct the study was obtained from all relevant authorities prior to commencement of the study.

During the main study, questionnaires were administered to students in their classrooms during their break time, with the help of two trained research assistants. The present study was conducted as part of a larger investigation concerning the inter-relationship between students' personality traits, religiousness/ spirituality, psychoactive substance use and psychological distress.

\section{Statistical analyses}

The data were coded and analyzed using the Statistical Package for Social Sciences version 16. The occupation of participants' parents/ guardians was classified using the International Standard Classification of Occupations (2008) by the International Labour Organization and was regrouped into 3 categories, namely; (1) more professional: comprising occupational groups 1 to 5, (2) less professional: composed of groups 0, 6 to 9, and (3) unemployed/deceased. Descriptive statistics were used to summarize data, and the " $t$ " test was used to test for the relationship between psychological distress and resilience, while other variables were tested using the chi square. All statistical evaluations were 2-tailed tests, with $\mathrm{p}$ values equal or less than 0.05 considered as significant.

\section{Results}

A total of 412 questionnaires were administered, of which 376 questionnaires were completed to allow for analysis, giving a response rate of $91.3 \%$. The female to male ratio was $1: 1.2$ and the mean age of the respondents was 16.9 years $(S D=0.9)$, with an age range of $16-19$ years.

One hundred and sixteen of the respondents scored 5 and above, referred to as 'GHQ cases', giving a prevalence rate of psychological distress of 30.9\% among the study group. There was a marginal significant difference $(\mathrm{t}=1.96, \mathrm{p}=0.05)$ in the resilience mean scores of the GHQ cases (33.87) and the non-cases (35.17) of the 300 participants who filled the adapted resilience scale.

\section{Associations between socio-demographic and family related factors and psychological distress}

There was no significant association between the presence of psychological distress and any of the sociodemographic/family-related characteristics (Tables 1,2).

\section{Discussion}

\section{Prevalence of psychological distress}

The prevalence rate of psychological distress in this study was $30.9 \%$, implying that three out of every ten school-going adolescents has a probability of being in psychological distress. This figure lies within the range of $15-50 \%$ prevalence of psychiatric morbidity reported in previous studies among Nigerian adolescents (6-8, Fatoye, 1998 \& Ikegwuonu, 2009, unpublished report). Previous Nigerian work by Taiwo (2011) reported a lower rate of $15 \%$, but this study differed in that it included school-going adolescents and used different measures, such as the Paediatric Symptom Checklist (PSC) (8). In contrast, our results are very similar to the rate of psychological distress $34.2 \%$ reported by Ikegwuonu (2009, unpublished report), which, although conducted in a different part of Nigeria, used a similar methodology to our study.

A key finding is that the prevalence rate of psychological distress in this study is higher than the range of $8-25 \%$ reported from many Western and Eastern countries $(16,29-34)$. The Nigerian adolescent population is growing up in a society which is in transition from traditional communal living-orientation to the individualistic Western technologically-oriented lifestyles; the associated psychosocial stressors are likely to contribute to the higher rate of psychological distress among Nigerian adolescents, compared to their counterparts in the developed world.

\section{Psychological distress and associated socio- demographics and family-related factors}

There was no significant gender difference in the 


\begin{tabular}{|c|c|c|c|c|}
\hline Variables & GHQ non-cases (\%) & GHQ cases $(\%)$ & Total (\%) & $p$ value \\
\hline Age years & & & & $x^{2}=2.07$ \\
\hline 16 & $118(70.2)$ & $50(29.8)$ & $168(100.0)$ & $\mathrm{df}=3$ \\
\hline 17 & 87 (71.9) & $34(28.1)$ & $121(100.0)$ & $p=0.56$ \\
\hline 18 & $36(62.1)$ & 22 (37.9) & $58(100.0)$ & \\
\hline 19 & $19(65.5)$ & $10(34.5)$ & $29(100.0)$ & \\
\hline Total & $260(69.1)$ & $116(30.9)$ & $376(100.0)$ & \\
\hline Gender & & & & $x^{2}=0.11$ \\
\hline Male & $141(68.4)$ & 65 (31.6) & 206 (100.0) & $d f=1$ \\
\hline Female & $119(70.0)$ & $51(30.0)$ & $170(100.0)$ & $p=0.75$ \\
\hline Total & $260(69.1)$ & $116(30.9)$ & $376(100.0)$ & \\
\hline Religion & & & & $x^{2}=5.27$ \\
\hline Christianity & $252(69.8)$ & $109(30.2)$ & 361 (100.0) & $\mathrm{df}=3$ \\
\hline Muslim & $6(50.0)$ & $6(50.0)$ & $12(100.0)$ & $p=0.15$ \\
\hline Traditional & $0(0.0)$ & $1(100.0)$ & $1(100.0)$ & \\
\hline Others & $2(100.0)$ & $0(0.0)$ & $2(100.0)$ & \\
\hline Total & $260(69.1)$ & $116(30.9)$ & $376(100.0)$ & \\
\hline School & & & & $x^{2}=0.21$ \\
\hline Public & $96(70.6)$ & $40(29.4)$ & $136(100.0)$ & $d f=1$ \\
\hline Private & $164(68.3)$ & $76(31.7)$ & $240(100.0)$ & $p=0.65$ \\
\hline Total & $260(69.1)$ & $116(30.9)$ & $376(100.0)$ & \\
\hline
\end{tabular}

\begin{tabular}{|c|c|c|c|c|}
\hline Variables & GHQ non-cases (\%) & GHQ cases $(\%)$ & Total (\%) & $p$ value \\
\hline Family & & & & $x^{2}=0.20$ \\
\hline Monogamous & $199(69.3)$ & $88(30.7)$ & $287(100.0)$ & $\mathrm{df}=1$ \\
\hline Polygamous & $61(68.5)$ & $28(31.5)$ & $89(100.0)$ & $p=0.89$ \\
\hline Total & $260(69.1)$ & $116(30.9)$ & $376(100.0)$ & \\
\hline Parents'/ guardians' religiosity & & & & $x^{2}=1.41$ \\
\hline Very religious & $207(68.3)$ & $96(31.7)$ & $303(100.0)$ & $\mathrm{df}=2$ \\
\hline Just religious & $45(75.0)$ & $15(25.0)$ & $60(100.0)$ & $p=0.49$ \\
\hline Not religious & $8(61.5)$ & $5(38.5)$ & $13(100.0)$ & \\
\hline Total & $260(69.1)$ & $116(30.9)$ & $376(100.0)$ & \\
\hline Living with & & & & $x^{2}=1.68$ \\
\hline Single parent & $42(75.0)$ & $14(25.0)$ & $56(100.0)$ & $\mathrm{df}=2$ \\
\hline Both parents & 167 (69.3) & 74 (30.7) & $241(100.0)$ & $p=0.43$ \\
\hline Guardian & $51(64.6)$ & $28(35.4)$ & 79 (100.0) & \\
\hline Total & $260(69.1)$ & $116(30.9)$ & $376(100.0)$ & \\
\hline Satisfactory relationship & & & & $x^{2}=197$ \\
\hline No & $29(60.4)$ & $19(39.6)$ & $48(100.0)$ & $\mathrm{df}=1$ \\
\hline Yes & $231(70.4)$ & 97 (29.6) & $328(100.0)$ & $p=0.16$ \\
\hline Total & $214(71.3)$ & $86(28.7)$ & $300(100.0)$ & \\
\hline Fathers' occupation & & & & $x^{2}=2.71$ \\
\hline More professional & $205(69.7)$ & $89(30.3)$ & $294(100.0)$ & $\mathrm{df}=2$ \\
\hline Less professional & $31(60.8)$ & $20(39.2)$ & $51(100.0)$ & $p=0.26$ \\
\hline Unemployed/dead & $24(77.4)$ & $7(22.6)$ & $31(100.0)$ & \\
\hline Total & $260(69.1)$ & $116(30.9)$ & $376(100.0)$ & \\
\hline Mothers' occupation & & & & $x^{2}=0.80$ \\
\hline More professional & $217(68.2)$ & $101(31.8)$ & $318(100.0)$ & $\mathrm{df}=2$ \\
\hline Less professional & $23(74.2)$ & $8(25.8)$ & $31(100.0)$ & $p=0.67$ \\
\hline Unemployed/dead & $20(74.1)$ & $7(25.9)$ & $27(100.0)$ & \\
\hline Total & $260(69.1)$ & $116(30.9)$ & $376(100.0)$ & \\
\hline
\end{tabular}


prevalence of psychological morbidity in this study. Previous data on this area have been inconsistent, with some studies reporting no association between gender and psychopathology $(29,34)$, while others have reported an association (17, 30, 31; Ikegwuonu, 2009, unpublished report).

Age was not significantly associated with GHQ cases in this study. Previous study findings regarding age have been inconsistent, with some researchers reporting no association (34, Ikegwuonu, 2009, unpublished report), and other reporting an association between age and psychological distress (16, 17, 31-32). Morita et al. (1993) reported a significantly higher prevalence of psychological distress in the younger age adolescent group (31) whereas Myklestad et al. (2011) found psychological distress to increase with increasing age of their subjects (17).

In our study, the type of school (public versus private) was not associated with the presence of psychological distress, which may have been influenced by the presence of numerous affordable private schools in the study location; as a result, pupils who attended private schools in our study were of both low and high socioeconomic status. Previous work by Ikegwuonu (2009) conducted in two Local Government Areas (LGAs) in South-East region of Nigeria, reported that while the type of school was not associated with psychological distress in the more rural LGA (similar to the results of this study), psychological distress was found to be significantly commoner in pupils attending public schools in the more urban LGA. Pupils who attend public schools are more likely to come from low socio-economic classes, which have been reported to be associated with more psychological distress $(15,16)$.

An attempt was made to derive the socio-economic status of the respondents by re-grouping the parents' occupational group to reflect this, but there was no association with psychological distress. Previous evidence regarding socioeconomic status and psychological distress has been conflicting; while some studies reported a relationship $(15,16)$ others have not $(33,34)$.

Religious affiliations (i.e., being a Christian or Muslim) were not significantly associated with psychological distress, once again implying that the respondents' mental health state is not influenced by their religious beliefs.

There was no significant association between familyrelated variables and the presence of psychological distress, although respondents from polygamous family background, those who stayed with guardians, those who were not satisfied with the relationship with their parents/guardians, and whose parents/guardians' religiosity were described as 'not religious', had a higher prevalence of psychological distress.

This study revealed a marginal association between psychological resilience with psychological distress, similar to previous findings (12). This highlights the importance of psychological resilience in mental health, and this is an area worth exploring further. However resilience is a complex construct that involves interaction between risk factors (adversities) and protective factors, which are both internal (personal assets) and external (environmental or ecological resources). Caution should therefore be exercised when interpreting resilience study findings. The core of resilience does not lie only within the individual's personal assets as focused on in this study (i.e. personal competence as resilience), but are also influenced by presence of environmental resources when in the presence of a risk factor.

\section{Study limitations}

This study was restricted to older adolescents who were in school, and findings therefore cannot generalized beyond this sample of adolescents. Secondly, factors such as environmental resources and risk factors were not considered during the assessment of psychological resilience in this study. Further, the categorization of the occupational groups may be unrepresentative of socioeconomic status. Lastly, the method of excluding chronic medical conditions was highly subjective. Future studies may need to adopt a more objective diagnostic measure to identify and exclude chronic physical illnesses.

\section{Conclusions}

A key finding of this study was that $30.9 \%$ of the surveyed adolescents had significant psychological distress. This was higher than the rates of psychological distress reported from the developed world. In this study, there was no significant association between sociodemographic/family characteristics and psychological distress; but the limitations of this study underscore the need to be cautious when interpreting these results, and it is inadvisable to conclude that these factors are unimportant in our understanding of the mental health state of adolescents. There is an important need for further resilience research as it is likely to have a role in development and implementation of mental health promotion programs.

\section{Conflicts of interest}

None declared

OO Akanni, Forensic Unit, Federal Neuropsychiatric Hospital, Benin City, Edo State, Nigeria

AN Otakpor, Department of Mental Health, University of Benin Teaching Hospital, Benin City, Edo State, Nigeria

Corresponding author: OO Akanni

Email: poppaul2002@yahoo.co.uk 


\section{References}

1. Windle G, Bennett KM, Noyes J. A methodological review of resilience measurement scales. Health Qual Life Out. 2011; 9: 8.

2. Davydov DM, Stewart R, Ritchie K, Chaudieu I. Resilience and mental health. Clin Psychol Rev 2010; 30(5): 479-95.

3. Waaktar T, Torgersen S. How resilient are resilience scales? The Big Five scales outperform resilience scales in predicting adjustment in adolescents. Scand J Psychol 2010; 51(2): 157-63.

4. World Health Organisation. Adolescents Development, c2013. Available at: http://www.who.int/maternal_child_ adolescent/topics/adolescence/dev/en/ [accessed Feb 2013]

5. Garaigordobil M. Psychopathological symptoms, social skills and personality traits: A study with adolescents. Span J Psychol 2006; 9(2): 182-92.

6. Gureje O, Omigbodun OO, Gater RA, Ikuesan BA, Morris J. Psychiatric disorders in a Paediatric Primary Care Clinic. Brit J Psychiatry 1994; 165(4): 527-30.

7. Adelekan M, Ndom R, Oluboka O. Epidemiology of childhood behavioural disorders in Ilorin, Nigeria - findings from parental reports. West Afr J Med 1999; 18: 39-48

8. Taiwo AO. Predictors of psychopathology among Nigerian adolescents: the role of psychosocial, demographics, personality and medical condition reports domains. Afr Health Sci 2011; 11(2): 228-39.

9. Hunter AJ. A Cross-Cultural Comparison of Resilience in Adolescents. J Paediatric Nursing 2000; 16(3): 172-9.

10. Hunter AJ, Chandler MJ. Adolescent Resilience. J Nurs Scholarsh 1999; 31(3): 243-7.

11. Irmansyah I, Dharmono S, Maramis SA, Minas H. Determinants of psychological morbidity in survivors of the earthquake and tsunami in Aceh and Nias. Int J Ment Health Syst 2010; 4: 8.

12. Abiola T, Udofia O. Psychometric assessment of the Wagnild and Young's resilience scale in Kano, Nigeria. BMC Research Notes 2011; 4: 509.

13. Cleverley K, Kidd SA. Resilience and suicidality among homeless youth. J Adolesc 2011; 34(5): 1049-54.

14. Parke RD. Development in the family. Annu Rev Psychol 2004; 55: 365-99.

15. Sawyer MG, Sarris A, Baghurst PA, Cornish CA, Kalucy RS. The prevalence of emotional and behavioral disorders and patterns of service utilization in children and adolescents. Aust NZ J Psychiatry 1990; 24: 323-30.

16. Frigerio A, Rucci P, Goodman R, et al. Prevalence and correlates of mental disorders among adolescents in Italy: the PrISMA study. Eur Child Adolesc Psychiatry 2009; 18(4): 217-26.

17. Myklestad I, Røysamb E, Tambs K. Risk and protective factors for psychological distress among adolescents: a family study in the Nord-Trøndelag Health Study. Soc Psychiatry Psychiatr Epidemiol 2011; 65(1): 57-63.

18. Otakpor AN, Akanni OO. Effects of personality traits, religiousness/spirituality on adolescent psychopathology in Benin City. Niger J Psychiatry 2015; 13(1): 37-44.

19. Vaughan JP, Morrow RH. Manual of epidemiology for district health management. WHO, Geneva 1989; 175-179.

20. Cadman D, Boyle M, Szatmari P, Offord DR. Chronic Illness, Disability, and Mental and Social Well-Being: Findings of the Ontario Child Health Study. Pediatrics 1987; 79(5): 805-13.

21. Goldberg DP. The Detection of Psychiatric Illness by Questionnaire. London: Oxford University Press; 1972.

22. Aderibigbe YA, Gureje O. The validity of the 28-item General Health Questionnaire in a Nigerian antenatal clinic. Soc Psychiatry Epidemiol 1992; 27(6): 280-3.

23. Ohaeri JU, Odejide OA, Gureje O, Olatawura MO. The prevalence of psychiatric morbidity among adult attendees at the five primary health care facilities of a rural community in Nigeria. Psychopathologie Africaine 1994; 26(1): 97-108.

24. Fatoye FO. Further observations on study difficulty among Nigerian students: psychological aspects and psychosocial correlates. Ife Psychologia 2005; 13(2): 204-18.

25. Osasona SO, Morakinyo O, Akhigbe KO. Study Difficulty amongst undergraduates in a Nigeria university: Pattern and relationship with psychiatric morbidity and academic performance. Niger J Psychiatry 2011; 9(3): 46-53.

26. Wagnild GM, Young HM. Development and psychometric evaluation of the resilience scale. J Nurs Meas 1993; 1(2): 165-78.

27. Ahern NR, Kiehl EM, Sole ML, Byers J. A review of instruments measuring resilience. Issues Compr Pediatr Nurs 2006; 29(2): 103-25.

28. Nunnaly J, Bernstein I. Psychometric Theory. New York: Mc Graw-Hill; 1994.

29. Kashani JH, Beck NC, Hoeper EW, et al. Psychiatric disorders in a community sample of adolescents. Am J Psychiatry 1987; 144(5): 584-89.

30. Fergusson DM, Horwood LJ, Lynskey MT. Prevalence and comorbidit of DSM-III-R diagnoses in a birth cohort of 15 year olds. J Am Acad Child Adolesc Psychiatry 1993; 32(6): 1127-34.

31. Morita H, Suzuki M, Suzuki S, Kamoshita S. Psychiatric disorders in Japanese secondary school children. J Child Psychol Psychiatry 1993; 34(3): 317-32

32. Roberts RE, Attkisson C, Rosenblatt A. Prevalence of psychopathology among children and adolescents. J Psychiatry 1998; 155(6): 715-25.

33. Eapen V, Swadi H, Sabri S, Abou-Saleir M. Childhood behavioural disturbance in a community sample in AlAin, United Arab Emirates. East Mediterr Health J. 2001; 7(3): 428-34.

34. Russell S, Subramanian B, Swamidhas P. Psychopathology and functional impairment among patients attending an adolescent health clinic: Implications for healthcare model reform. Ostheopath Med Pri Care 2008; 2: 3. 